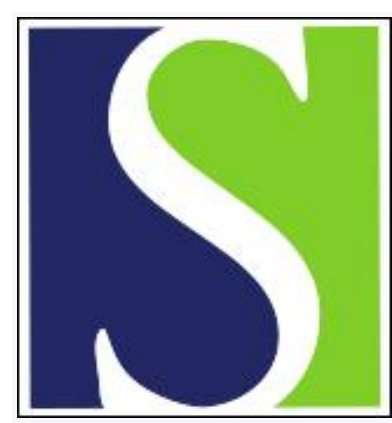

Scand J Work Environ Health 2011;37(5):427-436

https://doi.org/10.5271/sjweh.3142

Published online: 17 Jan 2011, Issue date: Sep 2011

Pesticide exposure and risk of Parkinson's disease - a population-based case-control study evaluating the potential for recall bias

by Rugbjerg K, Harris MA, Shen H, Marion SA, Tsui JKC, Teschke K

Affiliation: Institute of Cancer Epidemiology, Danish Cancer Society, DK-2100 Copenhagen, Denmark. rugbjerg@cancer.dk

The following articles refer to this text: 2012;38(1):65-69;

2017;43(3):197-209

Key terms: agricultural job; British Columbia; Canada; case-control study; exposure; job history; Parkinson's disease; pesticide; recall bias; self-report

This article in PubMed: www.ncbi.nlm.nih.gov/pubmed/21240453 


\title{
Pesticide exposure and risk of Parkinson's disease - a population-based case-control study evaluating the potential for recall bias
}

\author{
by Kathrine Rugbjerg, MSc, ${ }^{1}$ M Anne Harris, PhD, ${ }^{2}$ Hui Shen, PhD, ${ }^{2}$ Stephen A Marion, MD, ${ }^{2}$ Joseph KC \\ Tsui, MD, ${ }^{3}$ Kay Teschke, $P h D^{2}$
}

\begin{abstract}
Rugbjerg K, Harris MA, Shen H, Marion SA, Tsui JKC, Teschke K. Pesticide exposure and risk of Parkinson's disease - a population-based case-control study evaluating the potential for recall bias. Scand J Work Environ Health 2011;37(5):427-436. doi:10.5271/sjweh.3144
\end{abstract}

\begin{abstract}
Objective The aim of this study was to investigate whether pesticide exposure was associated with Parkinson's disease in a population-based case-control study in British Columbia, Canada.

Methods Patients reimbursed for anti-parkinsonian agents were identified and screened for eligibility as cases. Controls were selected from the universal health insurance database, frequency-matched to the case sample by birth year, gender, and geographic region. A total of 403 cases and 405 controls were interviewed about their job, medical and personal habits histories, and beliefs about disease risk factors. Among those reporting pesticide exposure, an occupational hygiene review selected participants exposed "beyond background" (ie, above the level expected in the general population). Unconditional logistic regression was used to estimate associations for different pesticide categories.
\end{abstract}

Results Of the cases, 74 (18\%) self-reported pesticide exposure and $37(9 \%)$ were judged to be exposed beyond background. Self-reported exposure was associated with increased risk [odds ratio (OR) 1.76, 95\% confidence interval $(95 \% \mathrm{CI}) 1.15-2.70$ ], however the risk estimate was reduced following the hygiene review when restricted to those considered exposed (OR 1.51, 95\% CI 0.85-2.69). When agricultural work was added to the model, the risk for hygiene-reviewed pesticide exposure was not elevated (OR $0.83,95 \%$ CI $0.43-1.61$ ), but agricultural work was (OR 2.47, 95\% CI 1.18-5.15). More than twice as many cases as controls thought chemicals cause Parkinson's disease.

Discussion This study provides little support for pesticide exposure as a cause of Parkinson's disease. The observed pattern of step-wise decreases in risk estimates might indicate differential recall by case status. The relationship to agricultural jobs suggests that farming exposures - other than pesticides - should be considered as risk factors for Parkinson's disease.

Key terms agricultural job; British Columbia; Canada; job history; self-report.

The etiology of Parkinson's disease is partly unknown, though $5-10 \%$ of the cases are attributed to genetic mutations (1). Parkinson's disease is thought to result from an interplay between genetic susceptibility and environmental risk factors (2). An association between pesticides and Parkinson's disease was first suspected in 1983, when the chemical 1-methyl-4-phenyl-1,2,3,6tetrahydropyridine (MPTP), which has a chemical structure similar to the herbicide paraquat, was observed to cause acute Parkinsonism (3). Since then, exposure to pesticides and subsequent development of Parkinson's disease has been studied intensively (eg, 4-17) and many studies $(4-8,12-17)$ have confirmed associations, though some were weak and not significant, and other studies did not find an effect $(9,10)$.

Methods of pesticide exposure ascertainment have varied from study to study, but it would be extraordinarily difficult to include direct exposure measurement due to the rarity and late-life incidence of Parkinson's disease. Retrospective self-reporting of exposures is the most commonly used method for estimation of pesticide exposure (4-10); however, this method has the

1 Danish Cancer Society, Institute of Cancer Epidemiology, Copenhagen, Denmark.

2 School of Population and Public Health, University of British Columbia, Vancouver, Canada.

3 Pacific Parkinson's Research Centre, University of British Columbia, Vancouver, Canada.

Correspondence to: Kathrine Rugbjerg, Institute of Cancer Epidemiology, Danish Cancer Society, Strandboulevarden 49, DK-2100 Copenhagen, Denmark. [E-mail: rugbjerg@cancer.dk] 
potential for recall bias (11). Some studies have gathered self-report of exposure prospectively $(12,13)$ or used more objective methods, such as job exposure matrices (14-16) or combinations of geographic information and historical data on pesticide use (17).

Here we report the results of a population-based case-control study of the relationship between pesticide exposure and Parkinson's disease. Self reports in combination with an occupational hygiene review were used to estimate exposures. We also investigated whether study participants believed that chemicals, including pesticides, cause Parkinson's disease and whether such a belief may have confounded exposure-response relationships.

\section{Methods}

\section{Study population}

Cases and controls were sampled from two areas of the province of British Columbia, Canada: Metro Vancouver representing an urban area (2.1 million people, population density 735 per $\mathrm{km}^{2}$ ); and all of Vancouver Island, except Greater Victoria, representing a rural area (400 000 people, population density $\sim 10$ per $\mathrm{km}^{2}$ ). The rural area was included to increase the diversity of occupations. Persons between the ages of 40-69 years inclusive (as of 31 December 2002) who were alive and residing in the study area at the time of interview and who were able to communicate with the interviewer in English were eligible. Subjects in the age group 40-69 years were chosen because they were less likely to suffer from dementia or other illnesses that could complicate an interview and because they were in, or close to, their working years and therefore more likely to recall exposures correctly.

Potential cases were identified using the PharmaCare database of the provincial prescription payment plan, which included all those who had more than CAN\$800 in prescription costs in a given year. For inclusion, individuals had to have had at least one prescription for antiparkinsonian drugs for at least one calendar year from 1995-2002 inclusive. The following were defined as antiparkinsonian drugs: levodopa, bromocriptine mesylate, pergolide mesylate, levodopa/benserazide hydrochloride, levodopa/carbidopa, or seligiline hydrochloride. The populations meeting the potential case definition were identified on two occasions: in 2001 (data from 1995-1998) and 2005 (data from 1999-2002). To blind the data extractors, the extract was supplemented with a $20 \%$ "camouflage" sample of other individuals in the database.

All potential cases were verified by an initial screening phone interview about chronic diseases, anti-parkinsonian drugs taken, and the reason for their use. This screened out those taking the drugs for much different purposes (eg, bromocriptine for lactation cessation or levodopa for restless legs syndrome). Those taking the drugs for known or suspected Parkinson's disease had an in-person physical assessment employing a checklist and record of symptoms, reviewed by a neurologist with a specialty in movement disorders. The following clinical criteria for Parkinson's disease were used: (i) two of the following symptoms present on examination: Parkinsonian tremor, rigidity, bradykinesia, masked facies, micrographia, or postural imbalance; (ii) absence of specific signs of other diseases that would account for these findings. Dates of Parkinson's disease diagnosis, first symptoms, and first treatment were also recorded.

The control sample was frequency-matched to the case sample on birth year (six 5-year periods), gender, and geographic region. Controls were selected using stratified random sampling from the British Columbia (BC) Ministry of Health Services client registry, which includes all individuals covered by provincial medical insurance and represents $97.5 \%$ of the population. All potential controls were screened by phone for eligibility, including a question about whether they had any chronic diseases. Anyone who indicated Parkinson's disease were excluded.

\section{Subject contact procedure}

This study was required to use a two-stage consent process. The BC Ministry of Health Services sent out invitation letters asking potential subjects to contact the University of $\mathrm{BC}$ team. If no response was received within two weeks of the mailing date, a clerk at the Ministry of Health Services phoned to ask the potential subject if their name could be released to the study team. Those who agreed were then contacted by the study coordinator who conducted the screening interview and requested study participation.

\section{Questionnaire information on pesticide exposure}

The questionnaire was pre-tested in several steps on a sample of 40 people selected to represent the age range of the subjects. The interviewers underwent formal training about all aspects of the interview, questionnaire, and clinical examination, and were observed during mock and initial interviews to ensure consistency.

In an in-person interview, participants were asked about their job, medical, and personal habits histories. The following questions were asked for all jobs: "During this job, did you use or were you exposed to any chemicals, for example, solvents, oils, plastics, paints, metals or pesticides?" As an aid to recall, an interview guide was sent to the participants prior to the interview and was referred to during the interview. It listed chemicals with an a priori hypothesis and included common and brand names (see the appendix for the list of pesticides). If a participant 
answered "yes", the following questions were asked: "Was this substance (i) breathed in, (ii) on skin, (iii) both, (iv) no direct contact, (v) don't know"; and "What operations were you performing when you were exposed to this substance?" for which a list of about 90 operations was provided in the interview guide. Participants were asked about weeks exposed per year, hours exposed per week, and start and end date of the exposure in that job. At the end of the interview, participants were asked: "What do you think causes Parkinson's disease?"

Each participant's job history was reviewed by an occupational hygienist (blind to case status) for sensitivity (ie, to check whether potential exposures of interest commonly associated with an occupation were reported). Where exposures were missed, the participant was phoned and asked about the exposures noted by the hygienist.

\section{Assigning exposure to pesticides}

After all interviews were completed, the self-reported exposures were again reviewed, blind to case status, this time for specificity. Using defined criteria and the information on job title, job duties, mode of exposure, operations conducted during exposure, and duration of exposure, assessments were made about whether self-reported pesticide exposures were likely to be "beyond background" or above the level expected in the general population. Of 121 persons who self-reported pesticide exposures, 53 were excluded because the reported exposure was judged to be limited. For example, sales personnel handling closed containers, construction workers occasionally handling wood treated with preservatives, and restaurant workers, security guards, administrative personnel, and care aides in locations where pesticides were occasionally applied by others were all judged to have limited exposure. In comparison, those judged to have exposures above background were mainly farmers, farm workers, forestry personnel, sawmill workers applying antisapstain fungicides, florists, and kennel and stable hands. Among those judged unlikely to be exposed beyond background, only $34 \%$ named a specific pesticide, whereas among those judged exposed, $73 \%$ did. A further 8 persons were excluded due to missing information on hours per week exposed $(\mathrm{N}=7)$ and whether the exposure was every week $(\mathrm{N}=1)$; on checking the job duties, it was likely that the information was missing because the exposure was rare in the job (eg, public health nurse applying lindane for lice)." Among those reporting exposure to pesticides, 60 were judged to be exposed beyond background.

\section{Categorizing pesticides}

Since most previous studies have categorized pesticides according to function (insecticides, herbicides, fungicides, and wood preservatives), for comparison purposes we did the same. We also created categories by chemical class: organochlorines and organophosphates. Finally, we grouped specific pesticides reported by the participants into two categories based on neurotoxicity (18-20): (i) pesticides with evidence of human neurotoxicity: allethrin, azinphosmethyl, diazinon, dichlorodiphenyltrichloroethane (DDT), 2,4-dichlorophenoxyacetic acid (2,4-D), dieldrin, glyphosate, lindane, malathion, 2-methyl-4-chlorophenoxyacetic acid (MCPA), nicotine, paraquat, pentachlorophenol, rotenone, tetrachlorophenol, and 2,4,5-trichlorophenoxyacetic acid (2,4,5-T); and (ii) pesticides with limited or no evidence of neurotoxicity: borax, brodifacoum, calcium polysulfide, captan, copper oxychloride, creosote, chromate copper arsenate, didecyl dimethyl ammonium chloride, lime sulphur, mineral oil, simazine, and sulphur. These categories were based on available evidence for neurotoxicity in case studies, animal studies, and in vitro studies (18-20).

\section{Statistical analysis}

Unconditional logistic regression was used to estimate associations with Parkinson's disease for different categories of pesticides: functional groups (insecticide, herbicide, fungicide, wood preservative); chemical groups (organophosphates, organochlorines); neurotoxic pesticides; and any specific pesticide reported by at least ten participants. In all analyses, persons reporting exposure to pesticides other than those relevant in the specific analysis were excluded.

Analyses were conducted for self-reported exposure and for hygiene-reviewed exposures beyond background. Analyses were performed for exposure via any job operation and for the subgroup reporting pesticide spraying operations. We also estimated risks with exposure duration and with censoring of exposures five and ten years prior to the date of diagnosis or the corresponding date for controls.

Finally, we estimated Parkinson's disease risk among those with agricultural jobs. Two adjustment models were used: model 1 adjusted for gender, birth year (5-year age groups), and smoking (cumulative pack-years); and model 2 adjusted for the same variables as model 1 in addition to a variable indicating whether the subject believed Parkinson's disease has a chemical cause.

Analyses were performed with SAS software version 9.1 (SAS Institute, Cary, NC, USA).

\section{Results}

A total of 3783 potential subjects were initially sent letters from the Ministry of Health Services. Figure 1 is a participation flowchart showing the classification of potential subjects. A large proportion of potential 
cases did not have Parkinson's disease (most used antiparkinsonian drugs for other indications). The multistage consent process resulted in uncertainty about the proportion of potential subjects who were eligible to participate. However, if we assume that the proportion of contacted subjects who were eligible $(554 / 1580=0.35$ for cases and $603 / 726=0.83$ for controls) was the same in the initially extracted samples, we can calculate the "potentially eligible" numbers $(0.35 \times 2261=791$ for cases; $0.83 \times 1522=1264$ for controls) and use these as denominators for the calculation of the participation rate. Using this method, the estimated participation rate was 403/791 (51\%) for cases and 405/1264 (32\%) for controls. The characteristics of the final study sample of 403 cases and 405 controls are summarized in table 1.

\section{Pesticide exposure}

Among cases, 74 (18\%) self-reported pesticide exposure and $37(9 \%)$ were judged to be exposed beyond background following the hygiene review. In the control group, $47(12 \%)$ self-reported pesticide exposure and 23 $(6 \%)$ were judged to be exposed beyond background. In both the case and control groups, insecticides and herbicides were the most frequently reported types of pesticides (table 1).

Table 2, model 1 (adjusted for birth year, gender and smoking) shows the results for both self-reported and hygiene-reviewed pesticide exposure via any job operation and spraying operations. For self-reported pesticide exposure, we found a significantly increased risk of Parkinson's disease. Among those judged exposed beyond background after the hygiene review, the odds ratio (OR) was lower than among those self-reporting exposure. In the hygiene-reviewed group, exposure via spraying pesticides had a higher risk estimate than via any job operation, though neither of these risk estimates were statistically significant. The risk estimates for subcategories of pesticides tended to follow similar patterns: the highest risk estimates were for self-reports; the hygiene review resulted in reductions in risk estimates; and there were slightly higher risk estimates for spraying exposures. None

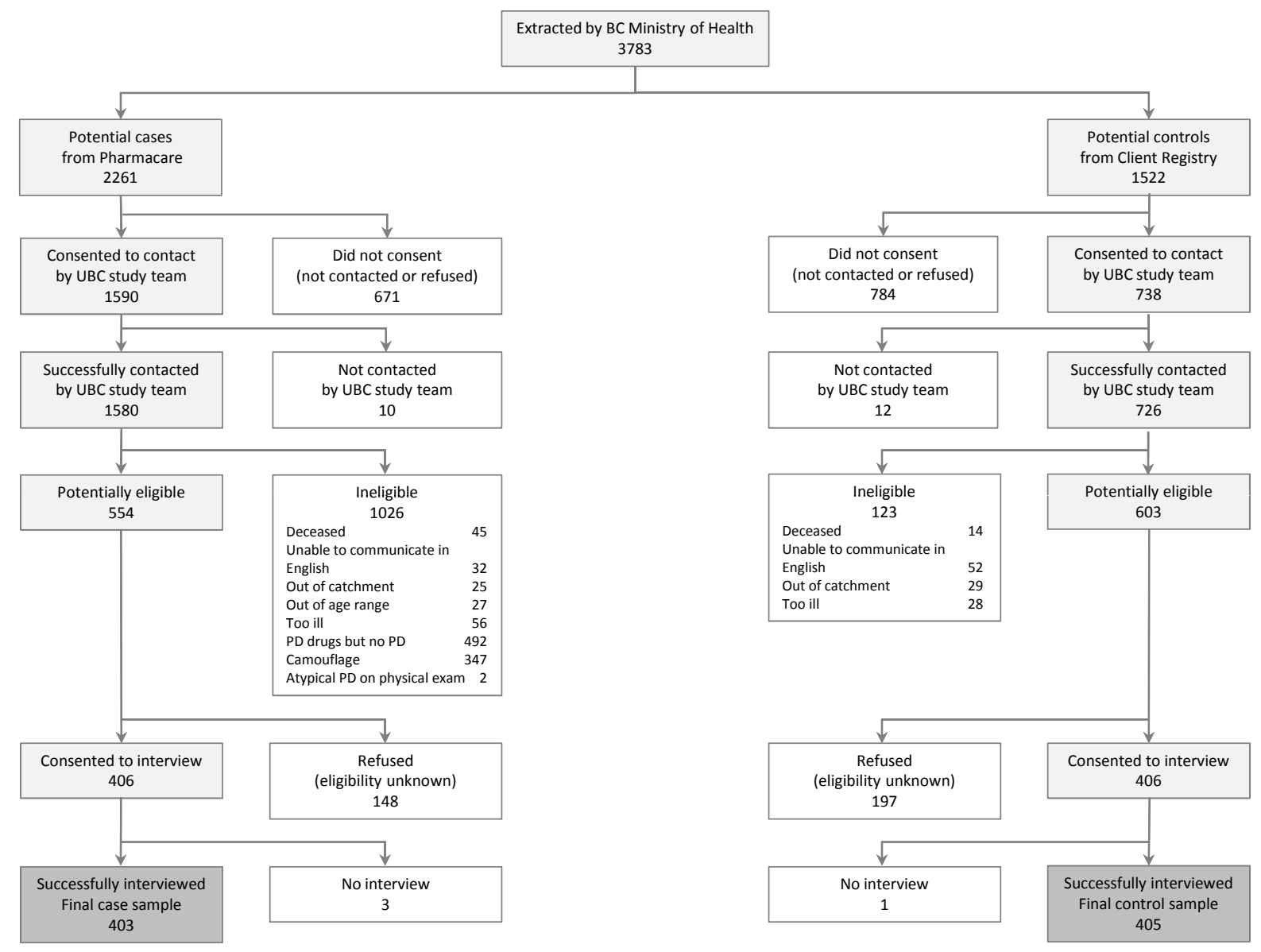

Figure 1. Flowchart showing the classification of potential participants in a case control study of Parkinson's disease in British Columbia, Canada. Potential cases were those with a prescription for antiparkinsonian drugs during the study period. 
Table 1. Characteristics of the study population: 403 patients with Parkinson's disease and 405 controls. [SD=standard deviation.]

\begin{tabular}{|c|c|c|c|c|c|c|c|c|}
\hline \multirow[t]{2}{*}{ Characteristic } & \multicolumn{4}{|c|}{ Cases } & \multicolumn{4}{|c|}{ Controls } \\
\hline & $\mathrm{N}$ & $\%$ & Mean & SD & $\mathrm{N}$ & $\%$ & Mean & SD \\
\hline Men & 266 & 66.0 & . & & 204 & 50.4 & & . \\
\hline Women & 137 & 34.0 & . & . & 201 & 49.6 & . & . \\
\hline \multicolumn{9}{|l|}{ Birth year } \\
\hline $1929-1938$ & 245 & 60.8 & . & . & 175 & 43.2 & . & . \\
\hline $1939-1948$ & 131 & 32.5 & . & . & 129 & 31.9 & . & $\cdot$ \\
\hline $1949-1958$ & 27 & 6.7 & . & . & 101 & 25.0 & . & . \\
\hline Geographic region: Metro Vancouver & 263 & 62.3 & $\cdot$ & & 242 & 59.8 & & . \\
\hline Self-reported pesticide exposure & 74 & 18.3 & . & . & 47 & 11.6 & . & · \\
\hline Hygiene-reviewed pesticide exposure & 37 & 9.2 & . & . & 23 & 5.7 & . & . \\
\hline Insecticides & 18 & 4.5 & . & . & 13 & 3.2 & . & . \\
\hline Herbicides & 17 & 4.2 & . & . & 13 & 3.2 & . & . \\
\hline Fungicides & 7 & 1.7 & . & . & 6 & 1.5 & . & . \\
\hline Wood preservatives & 10 & 2.5 & . & . & 5 & 1.2 & . & . \\
\hline No pesticide exposure & 329 & 81.6 & . & . & 358 & 88.4 & . & . \\
\hline Ever smoker a & 184 & 45.7 & . & . & 226 & 55.8 & & . \\
\hline $\begin{array}{l}\text { Named chemicals as cause of } \\
\text { Parkinson's disease }\end{array}$ & 111 & 27.5 & & $\cdot$ & 43 & 10.6 & . & $\cdot$ \\
\hline Smoking, cumulative pack-years & & & 11.4 & 20.4 & . & . & 15.4 & 22.4 \\
\hline $\begin{array}{l}\text { Mean age at diagnosis of Parkinson's } \\
\text { disease (years) }\end{array}$ & & & 56.0 & 7.1 & $\cdot$ & $\cdot$ & · & . \\
\hline Mean age at the time of interview (years) & & & 65.0 & 6.6 & . & . & 62.2 & 9.0 \\
\hline
\end{tabular}

a At least 100 cigarettes in the period prior to Parkinson's disease diagnosis and a corresponding period for controls.

of the OR for pesticide subcategories were statistically significant, except self-reported insecticide exposure. Risk estimates for hygiene-reviewed pesticide exposures were slightly above 1.0 in all categories of pesticides, except for organophosphates, organochlorines and DDT, however, most risk estimates had wide $95 \%$ confidence intervals $(95 \% \mathrm{CI})$ (table 2). Censoring exposures five and ten years prior to diagnosis did not change the risk estimates markedly (data not shown) and analyses including duration of pesticide exposure showed no significant associations with Parkinson's disease (data not shown).

We also examined the relationship between agricultural work and Parkinson's disease: 36 cases and 17 controls reported an agricultural job. Of these, 20 cases and 7 controls were exposed to pesticides. Participants who reported agricultural jobs had a significantly increased risk of Parkinson's disease (OR 2.36, 95\% CI 1.23-4.55, adjusted for gender, birth year and smoking). When the hygiene-reviewed pesticide exposures were added to this model, the elevated and statistically significant OR for agricultural work remained (OR 2.47, 95\% CI 1.18-5.15), but the risk for pesticide exposure was no longer elevated (OR 0.83, 95\% CI 0.43-1.61). A similar pattern held for each pesticide category: when added to a model with agricultural job, the elevated risk for the job remained, but the risk estimate for the pesticide was always $<1.0$. There were no significant interactions between agricultural job and any of the pesticide categories.
The analyses reported above suggest that differences in exposure recall between cases and controls may have contributed to the higher risk estimates for self-reported pesticide exposures, so we examined the responses to the question about what causes Parkinson's disease. A total of 154 participants reported "chemicals" as a suspected cause of Parkinson's disease (111 cases and 43 controls). Most did not name a specific class of chemical, however 21 participants specifically mentioned "pesticides" and all of these were cases. To see whether beliefs about causes of the disease might alter the association with pesticides, we conducted an additional set of analyses with adjustment for the participants' beliefs that chemicals are a cause of Parkinson's disease (table 2, model 2). The OR for pesticides in the model 2 analyses were consistently lower than those of model 1 , and none were statistically significant. In contrast, in analyses of agricultural job with adjustment for participants' beliefs that chemicals are a cause of the disease, the increased risk persisted (OR 2.28, 95\% CI 1.16-4.47).

\section{Discussion}

In this study, we observed significantly increased risks of Parkinson's disease with self-reported pesticide or insecticide exposures, but reductions in risk for those considered 
Table 2. Odds ratios $(\mathrm{OR})$ and $95 \%$ confidence intervals $(95 \% \mathrm{CI})$ for Parkinson's disease among persons who self-reported pesticide exposure and among those judged - by a hygiene review - to have pesticide exposure beyond background. Statistically significant OR in bold. [DDT= dichlorodiphenyltrichloroethane.]

\begin{tabular}{|c|c|c|c|c|c|c|c|c|c|c|c|c|c|c|c|c|c|c|}
\hline \multirow{3}{*}{$\begin{array}{l}\text { Pesticide } \\
\text { category }\end{array}$} & \multicolumn{9}{|c|}{ Model $1^{a}$} & \multicolumn{9}{|c|}{ Model $2^{b}$} \\
\hline & \multicolumn{3}{|c|}{$\begin{array}{l}\text { Self-reported exposure, } \\
\text { via any job operation }\end{array}$} & \multicolumn{3}{|c|}{$\begin{array}{c}\text { Hygiene-reviewed } \\
\text { exposure, via any job } \\
\text { operation }\end{array}$} & \multicolumn{3}{|c|}{$\begin{array}{c}\text { Hygiene-reviewed } \\
\text { exposure, spraying } \\
\text { operations }\end{array}$} & \multicolumn{3}{|c|}{$\begin{array}{l}\text { Self-reported } \\
\text { exposure, via any } \\
\text { job operation }\end{array}$} & \multicolumn{3}{|c|}{$\begin{array}{c}\text { Hygiene-reviewed } \\
\text { exposure, via any job } \\
\text { operation }\end{array}$} & \multicolumn{3}{|c|}{$\begin{array}{l}\text { Hygiene-reviewed } \\
\text { exposure, spraying } \\
\text { operations }\end{array}$} \\
\hline & $\mathrm{N}$ & OR & $95 \% \mathrm{Cl}$ & $\mathrm{N}$ & OR & $95 \% \mathrm{Cl}$ & $\mathrm{N}$ & $\mathrm{OR}$ & $95 \% \mathrm{Cl}$ & $\mathrm{N}$ & OR & $95 \% \mathrm{Cl}$ & $\mathrm{N}$ & $\mathrm{OR}$ & $95 \% \mathrm{Cl}$ & $\mathrm{N}$ & $\mathrm{OR}$ & $95 \% \mathrm{Cl}$ \\
\hline Pesticides & & 1.76 & $1.15-2.70$ & & 1.51 & $0.85-2.69$ & & 1.91 & $0.82-4.49$ & & 1.49 & $0.96-2.32$ & & 1.18 & $0.65-2.14$ & & 1.38 & $0.56-3.40$ \\
\hline Cases & 74 & & & 37 & & & 20 & & & 74 & & & 37 & & & 20 & & \\
\hline Controls & 47 & & & 23 & & & 9 & & & 47 & & & 23 & & & 9 & & \\
\hline Insecticides & & 1.80 & $1.03-3.15$ & & 1.26 & $0.58-2.74$ & & 1.86 & $0.66-5.24$ & & 1.44 & $0.81-2.58$ & & 0.86 & $0.38-1.93$ & & 1.24 & $0.42-3.65$ \\
\hline Cases & 40 & & & 18 & & & 13 & & & 40 & & & 18 & & & 13 & & \\
\hline Controls & 26 & & & 13 & & & 6 & & & 26 & & & 13 & & & 6 & & \\
\hline Herbicides & & 1.82 & $0.97-3.40$ & & 1.33 & $0.60-2.97$ & & 1.60 & $0.53-4.87$ & & 1.59 & $0.84-3.00$ & & 1.16 & $0.51-2.60$ & & 1.49 & $0.47-4.71$ \\
\hline Cases & 33 & & & 17 & & & 10 & & & 33 & & & 17 & & & 10 & & \\
\hline Controls & 19 & & & 13 & & & 6 & & & 19 & & & 14 & & & 6 & & \\
\hline Fungicides & & 0.94 & $0.38-2.32$ & & 1.18 & $0.35-4.00$ & & . & .. & & 0.80 & $0.31-2.03$ & & 0.95 & $0.27-3.31$ & & . & .. \\
\hline Cases & 11 & & & 7 & & & $3^{c}$ & & & 11 & & & 7 & & & $3^{c}$ & & \\
\hline Controls & 11 & & & 6 & & & $2^{c}$ & & & 11 & & & 6 & & & $2^{c}$ & & \\
\hline $\begin{array}{l}\text { Wood } \\
\text { preservatives }\end{array}$ & & 2.20 & $0.90-5.34$ & & 1.56 & $0.51-4.77$ & & . & .. & & 1.80 & $0.70-4.62$ & & 1.34 & $0.42-4.28$ & & . &.. \\
\hline Cases & 17 & & & 10 & & & $4^{c}$ & & & 17 & & & 10 & & & $4^{c}$ & & \\
\hline Controls & 9 & & & 5 & & & $0^{c}$ & & & 9 & & & 5 & & & $0^{c}$ & & \\
\hline $\begin{array}{l}\text { Organo- } \\
\text { phosphates }\end{array}$ & & 1.57 & $0.53-4.64$ & & 0.74 & $0.20-2.78$ & & . &.$\cdot$ & & 1.47 & $0.49-4.45$ & & 0.72 & $0.19-2.68$ & & . & .. \\
\hline Cases & 10 & & & 5 & & & $4^{c}$ & & & 10 & & & 5 & & & $4^{c}$ & & \\
\hline Controls & 6 & & & 5 & & & $3^{c}$ & & & 6 & & & 5 & & & $3^{c}$ & & \\
\hline $\begin{array}{l}\text { Organo- } \\
\text { chorines }\end{array}$ & & 1.23 & $0.53-2.85$ & & 0.62 & $0.19-2.00$ & & . &.. & & 1.05 & $0.44-2.52$ & & 0.38 & $0.11-1.31$ & & . & .. \\
\hline Cases & 16 & & & 6 & & & $5^{c}$ & & & 16 & & & 6 & & & $5^{c}$ & & \\
\hline Controls & 10 & & & 6 & & & $4^{c}$ & & & 10 & & & 6 & & & $4^{c}$ & & \\
\hline $\begin{array}{l}\text { Pesticides } \\
\text { with neuro- } \\
\text { toxic effects }\end{array}$ & & 1.76 & $0.95-3.25$ & & 1.08 & $0.49-2.36$ & & 1.34 & $0.53-3.40$ & & 1.48 & $0.78-0.80$ & & 0.86 & $0.38-1.93$ & & 1.06 & $0.40-2.82$ \\
\hline Cases & 35 & & & 17 & & & 14 & & & 35 & & & 17 & & & 14 & & \\
\hline Controls & 19 & & & 13 & & & 8 & & & 19 & & & 13 & & & 8 & & \\
\hline DDT & & 1.32 & $0.55-3.18$ & & 0.76 & $0.22-2.62$ & & . & .. & & 1.09 & $0.44-2.75$ & & 0.45 & $0.12-1.65$ & & . & .. \\
\hline Cases & 15 & & & 6 & & & $5^{c}$ & & & 15 & & & 6 & & & $5^{c}$ & & \\
\hline Controls & 9 & & & 5 & & & $3^{c}$ & & & 9 & & & 5 & & & $3^{c}$ & & \\
\hline
\end{tabular}

a Model 1: Adjusted for gender, birth year (5-year age groups), smoking (cumulative pack-years).

b Model 2: Adjusted for gender, birth year (5-year age groups), smoking (cumulative pack-years), and naming chemicals as a cause of Parkinson's disease.

${ }^{c}$ Fewer than ten subjects exposed, odds ratios and confidence intervals not reported.

exposed based on the hygiene review and when more specific categories of pesticides were mentioned. There were no increases in risk with censoring of exposures five and ten years prior to diagnosis, nor increasing risks with increasing duration of exposure. Only one pattern was suggestive of an association: the increases in risk for hygiene-reviewed exposures from "any job operation" to "spraying operations," though none of these OR were statistically significant. In analyses with agricultural job, pesticide exposures no longer had elevated OR. This pattern of results does not add convincing support to the proposed association between pesticides and Parkinson's disease and, for the most part, was counter to what would be expected to support pesticides as a cause.

Two patterns suggested the potential for recall bias to explain at least a portion of the observed associations between pesticide exposure and Parkinson's disease: decreases in risk between self-reported and hygienereviewed exposures and decreases in risk after adjustment for participants' belief that chemicals were a cause. In our study, $27.5 \%$ of cases with Parkinson's disease reported chemicals (including pesticides) as a cause of Parkinson's disease; the corresponding percentage for controls was $10.6 \%$. This difference indicates a greater suspicion of a chemical cause among cases than controls; the risk estimates for pesticide exposures decreased when controlling for this factor, meaning that suspecting a chemical cause was also associated with reporting pesticide exposure.

Evidence of recall bias in case-control studies has generally been sparse, except with open-ended 
questioning of exposure or where participants suspect a disease cause $(22,23)$. Difficulties in recall of pesticides have been shown to differ between cases and controls in a general population sample (24). Adjusting for suspicions of hypothesized causation may be inadvisable as a routine practice, particularly if knowledge is causally related to exposure or if exposed cases become knowledgeable about the hypotheses postdiagnosis (25). The former seems unlikely in our study, although the latter is possible, so we cannot know with certainty that the effect we observed was indeed due to recall bias.

Our results raise the question of whether the prior studies may have been subject to recall bias. Previous studies that, like ours, obtained information on exposure to pesticides from interviews have this potential (4-11, 21). Nevertheless, two cohort studies using prospective self-reports of exposure, which should not be prone to recall bias, found associations between exposure to pesticides as a group and risk of Parkinson's disease $(12,13)$.

Non-differential misclassification of exposure to pesticides is also an important issue, which could exist in our study and thus bias our results towards the null (26). Reducing non-differential misclassification of exposure was one of the purposes of the industrial hygiene review of exposures. We expected risk estimates to be higher for hygiene-reviewed than self-reported exposures, but the opposite was the case, initiating our suspicion of recall bias.

\section{Agricultural employment versus pesticide exposure: what is measured?}

We observed a significantly increased risk of Parkinson's disease among those reporting an agricultural job, with a risk estimate higher than those for pesticides. The finding for agricultural jobs was little influenced by adjustment for pesticide exposure or participants' beliefs that chemicals are a cause.

This raises the question of whether there is something else about agricultural work that might be related to Parkinson's disease. A number of studies (27-29), though not all (30), have reported associations between agricultural jobs and Parkinson's disease. Most investigators have related these associations to the use of pesticides in these jobs. However, a recent Australian study investigated the extent to which farm-related jobs indicated pesticide exposure (31) and found that only $22 \%$ likely had exposure. In our study, $51 \%$ of those in agricultural jobs were classified as "pesticide exposed". Farming jobs may share many other potential exposures, including solvents, fuels, fuel exhaust, dusts, micro-organisms, and traumatic injuries, many of which would be useful to examine in the context of Parkinson's disease. An exposure of particular interest could be endotoxin, a lipopolysaccharide component of gram-negative bacterial cell walls. Lange and coworkers (32) are among the researchers who have posited that part of the elevated risk of Parkinson's disease associated with agriculture could be explained by exposure to endotoxin because exposure is common in the agricultural sector and there is mechanistic support from animal experiments (33).

It would be worthwhile to consider the potential for other etiological exposures to explain at least some portion of the increased risks of Parkinson's disease observed among farmers or those assessed as being exposed to pesticide due to farming jobs $(12,14-16)$.

\section{Recent case-control studies}

In other recent case-control studies, the diversity of results related to pesticide exposures and agricultural work has continued. Elbaz and colleagues (4) found increased risks with professional pesticide use, especially insecticides, though they mentioned the possibility of increased awareness among cases of the possible link between Parkinson's disease and pesticides (4). Tanner et al (8) found increased risks for self-reported use of pesticides, increasing when restricted to eight specific pesticides with high neurotoxic plausibility (very similar to our classification), but agricultural work was not found to be a risk factor. Firestone and colleagues (10) found no significant association between self-reported exposure to pesticides or agricultural work and Parkinson's disease. Regional differences in exposure patterns between study populations and methodological differences (eg, different methods of ascertaining exposure) might partly explain these inconsistent results.

Despite the large number of studies investigating the possible association between pesticide exposure and Parkinson's disease, few epidemiological studies have found associations between exposure to a specific pesticide and Parkinson's disease. In a study using geographic information systems and historic information on pesticide use, exposure to the pesticides maneb and paraquat was found to be associated with risk of Parkinson's disease (17). To pinpoint specific pesticides in an interview based case-control study, the participants' memories need to be exceptional and the number of study participants needs to be very large. To illustrate the number of subjects needed to detect a significantly increased risk of Parkinson's disease for a specific pesticide, we calculated the sample size needed, using the pesticide with the highest proportion of controls exposed in this study [DDT (5 of 405)]. With a significance level of $5 \%$, power of $80 \%$ and equal numbers of cases and controls, 1500 cases and controls would be needed to detect an OR of 2.0. 


\section{Strengths and limitations}

Like most case-control studies, we had an in-person physical assessment of potential cases and included assessments of participants' lifestyle habits to allow control for smoking's negative association with Parkinson's disease (34). The assessment of pesticide exposure collected detailed information on the type of contact and operations performed enabling two hygiene reviews on sensitivity and specificity, respectively, both blind to case status. A list of pesticides with common names and brand names were provided to participants in advance to improve recall (see appendix) (22). Our study appears to be the only one to date that has attempted to evaluate recall bias based on participants' beliefs about the causes of Parkinson's disease.

A limitation of our study was the potential for participation bias, since those agreeing to take part in the study might differ from those refusing. Our study population was restricted to those in the age group 40-69 years, potentially limiting the generalizability of our results to older Parkinson's patients.

Further, our study was underpowered to detect 2-folddifference associations between subcategories of pesticide exposure with a prevalence of $<4 \%$ in controls. Most of our pesticide groups had sufficient power, but the number of participants who reported exposure to individual pesticides was very small, preventing analyses of most individual pesticides. The diversity of pesticide-active ingredients used by this study sample reflects the diversity of farming in the province, including fruit (apple, peaches, cherries, grapes, plums, blueberries, raspberries, cranberries), market vegetable (lettuce, tomatoes, sweet peppers, cucumbers, mushrooms), grain, and flower crop farming, as well as cattle ranching and dairy farming. The resulting variety of pesticides used is another factor that lessens the likelihood that pesticides are an important cause of Parkinson's disease in this population; there is little specificity of the chemicals. In addition, few of the study subjects had exposures to the pesticides used in animal models of Parkinson's disease (35): one case and four controls reported exposure to rotenone; three cases and three controls reported exposure to paraquat; and no one reported exposure to maneb.

In summary, the results of this study do not lend support for an association between pesticide exposure and Parkinson's disease. Our results emphasize the importance of considering recall bias via a hygiene review to ensure specificity of exposure ascertainment and by considering the participants' beliefs about the disease cause. The results related to agricultural work suggest that it would be valuable for future studies to explore other exposures of this occupational group that may be related to Parkinson's disease, such as bacterial endotoxin $(32,36)$.

\section{Acknowledgements}

We thank all the study participants whose generous gift of their time made this research possible. We thank the staff of the University of British Columbia and the BC Ministry of Health Services for their work on the study. The study was funded by WorkSafeBC, the Medical Research Council, and the Pacific Parkinson's Research Institute.

\section{References}

1. Biskup S, Gerlach M, Kupsch A, Reichmann H, Riederer P, Vieregge P, Wullner U, Gasser T. Genes associated with Parkinson syndrome. J Neurol. 2008 Sep;255 Suppl 5:8-17. doi:10.1007/s00415-008-5005-2.

2. Ross CA, Smith WW. Gene-environment interactions in Parkinson's disease. Parkinsonism Relat Disord. 2007;13 Suppl 3:S309-S315. doi:10.1016/S1353-8020(08)70022-1.

3. Langston JW, Ballard P, Tetrud JW, Irwin I. Chronic Parkinsonism in humans due to a product of meperidineanalog synthesis. Science 1983 Feb 25;219(4587):979-80. doi:10.1126/science. 6823561 .

4. Elbaz A, Clavel J, Rathouz PJ, Moisan F, Galanaud JP, Delemotte B, Alperovitch A, Tzourio C. Professional exposure to pesticides and Parkinson disease. Ann Neurol. 2009 Oct;66(4):494-504. doi:10.1002/ana.21717.

5. Frigerio R, Sanft KR, Grossardt BR, Peterson BJ, Elbaz A, Bower JH, Ahlskog JE, de AM, Maraganore DM, Rocca WA. Chemical exposures and Parkinson's disease: a populationbased case-control study. Mov Disord. 2006 Oct;21(10):168892. doi:10.1002/mds.21009.

6. Hancock DB, Martin ER, Mayhew GM, Stajich JM, Jewett R, Stacy MA, Scott BL, Vance JM, Scott WK. Pesticide exposure and risk of Parkinson's disease: a family-based case-control study. BMC Neurol. 2008;8:6. doi:10.1186/1471-2377-8-6.

7. Kamel F, Tanner C, Umbach D, Hoppin J, Alavanja M, Blair A, Comyns K, Goldman S, Korell M, Langston J, et al. Pesticide exposure and self-reported Parkinson's disease in the agricultural health study. Am J Epidemiol. 2007 Feb 15;165(4):364-74. doi:10.1093/aje/kwk024.

8. Tanner CM, Ross GW, Jewell SA, Hauser RA, Jankovic J, Factor SA, Bressman S, Deligtisch A, Marras C, Lyons KE, et al. Occupation and risk of parkinsonism: a multicenter case-control study. Arch Neurol. 2009 Sep;66(9):1106-13. doi:10.1001/archneurol.2009.195.

9. Firestone JA, Smith-Weller T, Franklin G, Swanson P, Longstreth WT, Jr., Checkoway H. Pesticides and risk of Parkinson disease: a population-based case-control study. Arch Neurol. 2005 Jan;62(1):91-5. doi:10.1001/archneur.62.1.91.

10. Firestone JA, Lundin JI, Powers KM, Smith-Weller T, Franklin GM, Swanson PD, Longstreth WT, Jr., Checkoway 
H. Occupational factors and risk of Parkinson's disease: A population-based case-control study. Am J Ind Med. 2010 Mar;53(3):217-23.

11. Drews CD, Greeland S. The impact of differential recall on the results of case-control studies. Int J Epidemiol. 1990 Dec;19(4):1107-12. doi:10.1093/ije/19.4.1107.

12. Petrovitch H, Ross GW, Abbott RD, Sanderson WT, Sharp DS, Tanner CM, Masaki KH, Blanchette PL, Popper JS, Foley D, et al. Plantation work and risk of Parkinson disease in a population-based longitudinal study. Arch Neurol. 2002 Nov;59(11):1787-92. doi:10.1001/archneur.59.11.1787.

13. Ascherio A, Chen H, Weisskopf MG, O'Reilly E, McCullough ML, Calle EE, Schwarzschild MA, Thun MJ. Pesticide exposure and risk for Parkinson's disease. Ann Neurol. 2006 Aug;60(2):197-203. doi:10.1002/ana.20904.

14. Dick FD, De PG, Ahmadi A, Scott NW, Prescott GJ, Bennett J, Semple S, Dick S, Counsell C, Mozzoni P, et al. Environmental risk factors for Parkinson's disease and parkinsonism: the Geoparkinson study. Occup Environ Med. 2007 Oct;64(10):666-72. doi:10.1136/oem.2006.027003.

15. Seidler A, Hellenbrand W, Robra BP, Vieregge P, Nischan P, Joerg J, Oertel WH, Ulm G, Schneider E. Possible environmental, occupational, and other etiologic factors for Parkinson's disease: a case-control study in Germany. Neurology. 1996 May;46(5):1275-84.

16. Baldi I, Cantagrel A, Lebailly P, Tison F, Dubroca B, Chrysostome V, Dartigues JF, Brochard P. Association between Parkinson's disease and exposure to pesticides in southwestern France. Neuroepidemiology. 2003 Sep;22(5):305-10. doi:10.1159/000071194.

17. Costello S, Cockburn M, Bronstein J, Zhang X, Ritz B. Parkinson's disease and residential exposure to maneb and paraquat from agricultural applications in the central valley of California. Am J Epidemiol. 2009 Apr 15;169(8):919-26. doi:10.1093/aje/kwp006.

18. Hallenbeck WH, Cunningham-Burns KM. Pesticides and human health. New York: Springer-Verlag; 1985.

19. Ecobichon Dj. Toxic effects of pesticides. In Cararett and Doull's Toxicology. 5 ed. USA: The McGraw-Hill Companies, Inc; 2001. p763-810.

20. CHE. The Collaborative on Health and the Environment 2009 [homepage]. Available online: www.healthandenvironment. org. Accessed 3 January 2011.

21. Blair A, Zahm SH. Patterns of pesticide use among farmers: implications for epidemiologic research. Epidemiology. 1993 Jan;4(1):55-62. doi:10.1097/00001648-199301000-00011.

22. Teschke K, Olshan AF, Daniels JL, De Roos AJ, Parks CG, Schulz M, Vaughan TL. Occupational exposure assessment in case-control studies: opportunities for improvement. Occup Environ Med. 2002 Sep;59(9):575-93. doi:10.1136/ oem.59.9.575.

23. Infante-Rivard C, Jacques L. Empirical study of parental recall bias. Am J Epidemiol. 2000 Sep 1;152(5):480-6. doi:10.1093/ aje/152.5.480.

24. Rodvall Y, Ahlbom A, Spannare B, Nise G. Glioma and occupational exposure in Sweden, a case-control study. Occup Environ Med. 1996 Aug;53(8):526-32. doi:10.1136/ oem.53.8.526.

25. Weiss NS. Should we consider a subject's knowledge of the etiologic hypothesis in the analysis of case-control studies? Am J Epidemiol. 1994 Feb 1;139(3):247-9.

26. Rothman KJ, Greenland S, Lash TL. Validity in Epidemiologic studies. In: Rothman KJ, Greenland S, Lash TL, editors. Modern Epidemiology. 3rd ed. Philadelphia: Wolters Kluwer; 2008. p128-47.

27. Park J, Yoo CI, Sim CS, Kim HK, Kim JW, Jeon BS, Kim KR, Bang OY, Lee WY, Yi Y, et al. Occupations and Parkinson's disease: a multi-center case-control study in South Korea. Neurotoxicology. 2005 Jan;26(1):99-105. doi:10.1016/j. neuro.2004.07.001.

28. Gorell JM, Peterson EL, Rybicki BA, Johnson CC. Multiple risk factors for Parkinson's disease. J Neurol Sci. 2004 Feb 15;217(2):169-74. doi:10.1016/j.jns.2003.09.014.

29. Goldman SM, Tanner CM, Olanow CW, Watts RL, Field RD, Langston JW. Occupation and parkinsonism in three movement disorders clinics. Neurology. 2005 Nov 8;65(9):1430-5. doi:10.1212/01.wnl.0000180361.74060.70.

30. Rocca WA, Anderson DW, Meneghini F, Grigoletto F, Morgante L, Reggio A, Savettieri G, Di PR. Occupation, education, and Parkinson's disease: a case-control study in an Italian population. Mov Disord. 1996 Mar;11(2):201-6. doi:10.1002/mds.870110214.

31. MacFarlane E, Glass D, Fritschi L. Is farm-related job title an adequate surrogate for pesticide exposure in occupational cancer epidemiology? Occup Environ Med. 2009 Aug;66(8):497-501. doi:10.1136/oem.2008.041566.

32. Lange JH, Buja A, Mastrangelo G. Endotoxin, a possible agent in the causation of Parkinson's disease. J Occup Environ Med. 2006 Jul;48(7):655-6. doi:10.1097/01. jom.0000214446.94586.62.

33. Castano A, Herrera AJ, Cano J, Machado A. The degenerative effect of a single intranigral injection of LPS on the dopaminergic system is prevented by dexamethasone, and not mimicked by rh-TNF-alpha, IL-1beta and IFN-gamma. J Neurochem. 2002 Apr;81(1):150-7. doi:10.1046/j.14714159.2002.00799.x

34. Thacker EL, O'Reilly EJ, Weisskopf MG, Chen H, Schwarzschild MA, McCullough ML, Calle EE, Thun MJ, Ascherio A. Temporal relationship between cigarette smoking and risk of Parkinson disease. Neurology. 2007 Mar 6;68(10):764-8. doi:10.1212/01.wnl.0000256374.50227.4b.

35. Cicchetti F, Drouin-Ouellet J, Gross RE. Environmental toxins and Parkinson's disease: what have we learned from pesticide-induced animal models? Trends Pharmacol Sci. 2009 Sep;30(9):475-83. doi:10.1016/j.tips.2009.06.005.

36. Niehaus I, Lange JH. Endotoxin: is it an environmental factor in the cause of Parkinson's disease? Occup Environ Med. 2003 May;60(5):378. doi:10.1136/oem.60.5.378.

Received for publication: 19 October 2010 
Appendix. List of pesticides sent out to the participants prior to the interview.

\begin{tabular}{|c|c|}
\hline Chemical name & Brand and common names \\
\hline \multicolumn{2}{|l|}{ Fungicides } \\
\hline Captan & Agrox D-L Plus, Orthocide \\
\hline Chlorothalonil & Bravo, daconil 2787, Exotherm Termil, Termil \\
\hline Copper oxychloride & Basicop, Coprantol, Fixed copper, mar-cop, neutron-Cop, Tri-Cop \\
\hline Dodine & Cyprex, Equal \\
\hline Formaldehyde & Formalin, Methanol \\
\hline $\begin{array}{l}\text { Lime sulphur or calcium } \\
\text { polysulphide }\end{array}$ & Orthorix \\
\hline Mancozeb & Dithane M-45, manzate 200 \\
\hline Maneb & Co-op DP, Ditane M-22, Mantox, Manzae, Mergamma, Pool NM Dual, Tersan LSRF \\
\hline Metam & Pole-Fume, SMDC, Unifume Soil, Vapam, VPM, Woodfume \\
\hline Metiram & Polyram \\
\hline Quintozene & Brassicol, PCNB, terrachlor \\
\hline Sulphur & Flortex, Giant Destroyer, Gopher Gasser, Kolodust, Kolospray, Magnetic 6, Ortho Flotox, Woodchuck Bombs \\
\hline Ziram & Zerate \\
\hline \multicolumn{2}{|c|}{ Herbicides and plant growth regulators } \\
\hline $2,4,5-T$ & $\begin{array}{l}\text { Dacamine-4T, Esteron 2,4,5-T, Poison Ivy and Brush Killer, Reddox, Trinoxol, Veon, Verton 2T, Weedone } \\
\text { 2,4,5-T }\end{array}$ \\
\hline 2,4-D & $\begin{array}{l}\text { 2,4-D, Amkil, Aqua-Kleen, Calmix, Chlorxone, Dacamine, Desormone 7, Diachlorprop, Driamine, Estakil, } \\
\text { Estasol, Estemine 500, Esteron, Esteron } 64 \text {, Foestamine, For-ester, Formula 40-F, Herbate, Hoe-Grass, Kilmor, } \\
\text { Rustler, Salvo, Silvaprop, Sure-Shot Forest amine, Target, Ten-Ten, Verton, Weedar, Weedar-64, Weedaway, } \\
\text { Weed-B-Gone, Weedex, Weedone, Weed-Rhap }\end{array}$ \\
\hline Atrazine & Aatrex, Atra-Mix, Eramox 80W, gesaprim, Laddox, Marzone, Primatol A, Primextra, Vectal Atrazine \\
\hline Bifenox & , \\
\hline Chlormequat & Cycocel \\
\hline Difenzoquat & Avenge \\
\hline Diquat & Reglone, Reglone-A, Weedrite \\
\hline Ethalfluralin & Edge \\
\hline Glyfosate & Roundup, Rustler, Side-Kick, Vision \\
\hline MCPA amine & $\begin{array}{l}\text { Agritox, Agroxone, Bromox, Buctril, Estemine MCPA, Estakil MCPA, MCP, Mephanac, Methoxone Amine 500, } \\
\text { No Weed, Sabre, Weedar MCPA, Weedgone MCPA }\end{array}$ \\
\hline Metolachlor & Dual, Primextra \\
\hline Morfamquat & Morfoxone \\
\hline Norflurazon & Evitol, Zorial \\
\hline Paraquat & Gramoxone, Gramoxone S, Paraquat CL, Sweep, Terraklene, Weed Rite \\
\hline Simazine & Gestatop, Primatol S, Princep, Simmaprim, Simadex \\
\hline Sodium chlorate & Atlacide, Atratol, Chlorax, Monobor-Chlorate, Ureabor \\
\hline $\begin{array}{l}\text { Sodium metaborate tetrahydrate } \\
\text { Triallate }\end{array}$ & Borate, Ureabor \\
\hline \multicolumn{2}{|l|}{ Insecticides } \\
\hline Allethrin & Allethrin, Synthetic Pyrethrin \\
\hline Azinphos-methyl & APM, Gurhion \\
\hline Cypermethrin & Ripcord \\
\hline Dichlorodiphenyltrichloroethane & DDT \\
\hline Diazinon & Basudin \\
\hline Dieldrin & Dieldrin \\
\hline Heptachlor & Heptachlor \\
\hline Lindane & $\begin{array}{l}\text { Agrox D-L Plus, Benolin, Co-op DP, Gamma BHC, Gammasan, Mergamma, Pool NM Dual, Thiralin, Vitaflo DP, } \\
\text { Vitavax }\end{array}$ \\
\hline Malathion & Cythion \\
\hline Mineral oil & $\begin{array}{l}\text { Agricultural Weedkiller \#1, Dormant Oils, Petroleum Oils, Petroleum Solvents, Stoddart Solvents, Summer Oil, } \\
\text { Superior Oil, Supreme Oil, Volck Oil, Weed Oils }\end{array}$ \\
\hline Nicotine & Black Leaf 40 , Nicotine, Nicotine Sulfate \\
\hline Rotenone & Atox, Deritox, Derris, Noxfish Fish Toxicant, Rotenone Fish Poison \\
\hline \multicolumn{2}{|l|}{ Wood preservatives } \\
\hline 3-iodo-2-propyl butyl carbamate & IPBC, NP-1, Troysan Polyphase P 100, Troysan Polyphase \\
\hline $\begin{array}{l}\text { Borax } \\
\text { Chromated copper arsenate }\end{array}$ & $\begin{array}{l}\text { Borascu, Boron, Ecobrite, Ecobrite A, Ecobrite B, Ecobrite C, Ecobrite II, Ecobrite III, F-2, Pole-Peg } \\
\text { CCA }\end{array}$ \\
\hline Creosote & Coal Tar Creosote, Pole-Peg \\
\hline $\begin{array}{l}\text { Didecyl dimethyl } \\
\text { ammonium chloride }\end{array}$ & DDAC, Ecobrite III, F-2, NP-1, Timbercote II, Timbercote 2000 \\
\hline Pentachlorophenol & Alchem, Dowwicide, Diatox, PCP, Penta, Pole-Peg, Santobrite, Woodbrite, Woodsheath \\
\hline Sodium carbonate & Ecobrite, Ecobrite A, Ecobrite B, Ecobrite C, Ecobrite II, SCB \\
\hline \multicolumn{2}{|l|}{ Rodenticides } \\
\hline $\begin{array}{l}\text { Brodifacoum } \\
\text { Bromadiolone }\end{array}$ & Ratak, Talon \\
\hline \multicolumn{2}{|l|}{ Fumigants } \\
\hline Methyl bromide & Brom-0-Gas, Dowfume, Dowfume MC-2, Meth-0-Gas, Sanex MB-C-2, Terr-0-Gas 67 \\
\hline Carbon disulfide & Dowfume, FIA 80-2, Kenfume bin fumigant, Sanifume \\
\hline Hydrogen cyanide & Cyanogas, calcium cyanide, HCN \\
\hline
\end{tabular}

